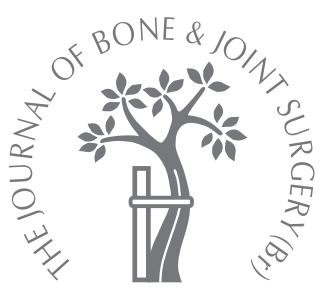

N. Shetty,

A. J. Hamer,

I. Stockley,

R. Eastell,

J. M. Wilkinson

From The Northern

General Hospital, Sheffield, England
N. Shetty, MRCS, Research Fellow

A. J. Hamer, MD, FRCS(Orth), Consultant Orthopaedic

Surgeon

I. Stockley, MD, FRCS, Consultant Orthopaedic

Surgeon

J. M. Willkinson, PhD, FRCS(Orth), Hip Fellow Department of Orthopaedics R. Eastell, MD, FRCP, Professor of Bone Metabolism Academic Unit of Bone

Metabolism, Division of Clinical Sciences (North)

University of Sheffield, Northern General Hospital, Herries Road, Sheffield, S5 7AU, UK.

Correspondence should be sent to $\mathrm{Mr} \mathrm{J}$. M. Wilkinson; e-mail: wilkomark@aol.com

(C2006 British Editorial Society of Bone and Joint Surgery doi:10.1302/0301-620X.88B10. $17308 \$ 2.00$

$J$ Bone Joint Surg [Br] 2006;88-B:1309-15.

Received 14 October 2005;

Accepted after revision 14 June 2006

\title{
Clinical and radiological outcome of total hip replacement five years after pamidronate therapy
}

\author{
A TRIAL EXTENSION
}

Bisphosphonates reduce peri-prosthetic bone loss in the short term after total hip replacement but the mid- and longer term effects are not known. The aims of this randomised trial were to examine the effect of a single dose of $90 \mathrm{mg}$ of pamidronate on the clinical and radiological outcome and peri-prosthetic bone mineral density in $\mathbf{5 0}$ patients ( 56 hips) over a five-year period, following total hip replacement.

At five years, 37 patients (42 hips) returned for assessment. The Harris hip scores were similar in the pamidronate and placebo groups throughout the study. Also at five years, four patients, two from each group had osteolytic lesions on plain radiography. These were located around the acetabular component in three patients and in the femoral calcar in one. The femoral and acetabular peri-prosthetic bone mineral density in the pamidronate group and the control group was similar at five years.

Pamidronate given as a single post-operative dose does not appear to influence the clinical outcome or prevent the development of osteolytic lesions at five years after total hip replacement.

Peri-prosthetic osteolysis contributes to aseptic loosening after total hip replacement (THR). At present, the only established treatment for osteolysis is revision surgery. As a result, many strategies of treatment are being developed in the hope that these may reduce the incidence of, or arrest the progression of, osteolysis. Potential approaches include the use of surfaces, such as hard-on-hard bearings or highly cross-linked polyethylene which have a low rate of wear, ${ }^{1,2}$ improvement of fixation of the implant by the use of osteoconductive or osteoinductive surface coatings, ${ }^{3}$ or pharmacological intervention to preserve peri-prosthetic bone mineral density (BMD). ${ }^{4}$ The role of pharmacological and biological agents in modulating the progression of established osteolytic lesions is also being explored. ${ }^{5-10}$

To date, the most extensively investigated group of drugs with a potential role in modulating bone loss and osteolysis is the bisphosphonates, which have powerful anti-osteoclastic activity. ${ }^{11} \mathrm{We}$, and other investigators, have found that they reduce early bone loss after total joint replacement. ${ }^{12-17}$ In a recent meta-analysis of six studies which met the eligibility criteria, Bhandari et $\mathrm{al}^{4}$ concluded that bisphosphonates preserved bone mass in the early period after surgery. However, they also highlighted the short-term nature and a lack of relevant outcomes such as clinical function, quality of life and survivorship data, in these studies.

In a previous paper we concluded that a single post-operative infusion of $90 \mathrm{mg}$ of pamidronate reduced femoral bone loss and active turnover of systemic bone over a period of two years, but did not enhance early stability of the implant. ${ }^{13}$ The aims of this five-year clinical trial were to study the longer term effects of treatment with pamidronate on the clinical and radiological outcome, and on peri-prosthetic bone loss as measured by dual-energy $\mathrm{x}$-ray absorptiometry (DEXA).

\section{Patients and Methods}

Between April and October 1998, 50 patients with a diagnosis of primary or secondary osteoarthritis were recruited for the study. Those with inflammatory arthritis, disorders affecting bone turnover, or an intake of drugs affecting bone turnover within the preceding 12 months were excluded. The investigation was approved by the local research ethics committee. All patients gave written informed consent.

All patients received a 'hybrid' THR with a cemented femoral component (Ultima-TPS; DePuy Ltd, Leeds, United Kingdom) and a cementless press-fit acetabular component 
Table I. Details of the treatment and control groups

\begin{tabular}{llll}
\hline & Treatment & Control & p-value \\
\hline Number of patients & 18 & 19 & 3 \\
Number of bilateral THRs* & 2 & 57 (28 to 71$)$ & 0.795 \\
Mean age in years (range) & 58 (32 to 73) & $10: 9$ & 0.508 \\
Male:Female & $12: 6$ & 29 (24 to 37$)$ & 0.155 \\
Mean body mass index in $\mathrm{kg} / \mathrm{m}^{2}$ (range) & 27 (19 to 38) & $1.77(1.34$ to 2.30$)$ & 0.727 \\
Mean pre-operative BMD ${ }^{\dagger}$ in $\mathrm{g} / \mathrm{cm}^{2}$ (range) & & $1.12(0.96$ to 1.71$)$ & 0.682 \\
$\quad$ Net proximal femur & $1.80(1.43$ to 2.07$)$ & $0.60(0.22$ to 3.48$)$ & 0.204 \\
$\quad$ Net pelvis & $1.14(0.67$ to 1.56$)$ & &
\end{tabular}

(Plasma cup; Braun Ltd, Sheffield, United Kingdom), except two, in whom press-fit stability was not achieved; they received a cemented Charnley acetabular component (DePuy Ltd). Details of the operative procedure and the post-operative regime of mobilisation have been described previously. ${ }^{12}$ Patients were randomised to receive either a single intravenous infusion of $90 \mathrm{mg}$ of pamidronate (Novartis Pharmaceuticals UK Ltd., Frimley, United Kingdom) or a placebo using a computer-generated, simple randomisation design. Both were prepared in the hospital pharmacy, supplied as a colourless solution in $500 \mathrm{ml}$ of $0.9 \%$ sodium chloride and administered on the fifth postoperative day.

Clinical and radiological assessment. Clinical assessments were made using the Harris hip score ${ }^{18}$ pre-operatively and at 12 and 26 weeks and one, two and five years after operation. Standardised supine anteroposterior (AP) radiographs of the pelvis and proximal femur were taken at the post-operative baseline and at 6,12 and 26 weeks and one, two and five years. The location of any osteolytic lesions around the pelvic implant was categorised using the zones described by DeLee and Charnley, ${ }^{19}$ and of any femoral peri-prosthetic osteolytic lesions by the zones described by Gruen, McNiece and Amstutz. ${ }^{20}$ Measurements of the size of the lesion were made using a metric digital electronic calliper with outside-inside jaws, a manufacturer's precision of $\pm 0.01 \mathrm{~mm}$ and an accuracy of $\pm 0.02 \mathrm{~mm}$ (model KEN331-1330 K; Kennedy Tools, Sheffield, United Kingdom). Measurements were corrected for magnification by using the known size of the femoral head, and expressed in millimetres as the maximum width and length of the osteolytic lesion. The radiographs were then digitised using a laser digitiser (Lumniscan 200; Lumnisys Inc., Sunnyvale, California) and the wear of the acetabular component was measured using EBRA software (EBRA-Cup 1998 release, University of Innsbruck, Austria) by the method described previously. ${ }^{21}$

Bone densitometry. The patients underwent baseline DEXA scans of the proximal femur and hemipelvis one week after operation and had follow-up scans at 6,12 and 26 weeks and one, two and five years. The scans were acquired and analysed using a Hologic QDR 4500-A fan-beam densito- meter (Hologic Inc., Bedford, Massachusetts) in 'metalremoval' scanning mode according to an established protocol. $^{22}$ The BMD was measured in seven contiguous regions of interest around the femoral implant and in four around the acetabular implant. ${ }^{23}$ The terms 'net femoral' and 'net acetabular' region of interest defined a global region around each implant. Manual exclusion was performed on areas containing heterotopic bone from the analysis of regions of interest, as described previously. ${ }^{12}$

The DEXA scans acquired at five years were analysed using a Windows version of the Hologic software (version 11.2; Hologic Inc.), while the previous scans were assessed using DOS software (version 8.0; Hologic Inc.). Previous analysis of femoral and acetabular scans in an independent group of 29 patients after THR has determined that no calibration correction is necessary for measurements made using the Windows software. ${ }^{24}$

Statistical analysis. All analyses were made on a 'perpatient' basis. When a patient had received bilateral THRs, values for the change in the BMD were expressed as the mean change for both hips. Analysis of serial numerical data was made by repeated-measures analysis of variance (ANOVA) and that of categorical data by the chi-squared test. All analyses were two-tailed using a critical p-value of 0.05 and were conducted using SPSS software version 12 (SPSS UK Ltd, Woking, United Kingdom).

\section{Results}

Of the 50 patients recruited, 37 (74\%) returned for assessment at five years. All had received a hybrid THR. In five, bilateral simultaneous THR had been performed, giving a total of 42 hips available for analysis. The baseline characteristics of the control and treatment groups were similar (Table I). At five years, six patients had died and three were withdrawn for violations of the protocol. Of these three, one had a traumatic fracture in the early post-operative period, one was diagnosed with inflammatory arthropathy and the other one developed temporal arteritis requiring systemic steroid therapy. Two others (one from each group) declined review and two were lost to follow-up.

Clinical and radiological assessment. The median Harris hip scores were similar in the treatment groups throughout the 


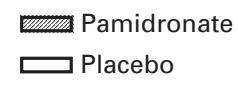

Pamidronat
Placebo

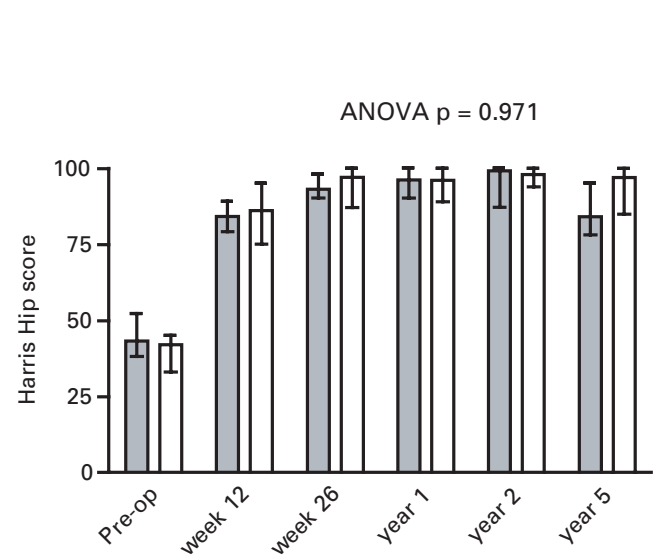

a

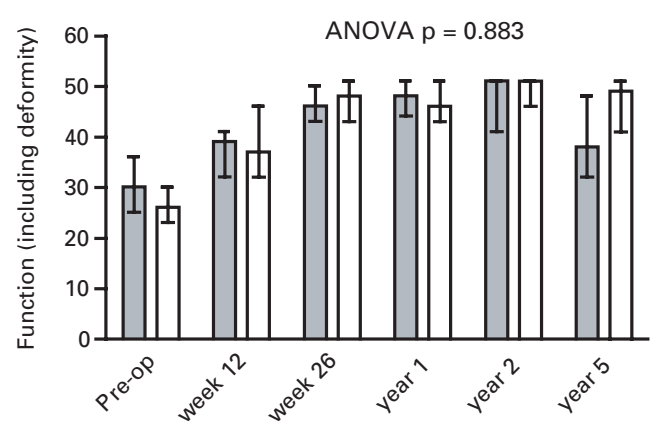

C

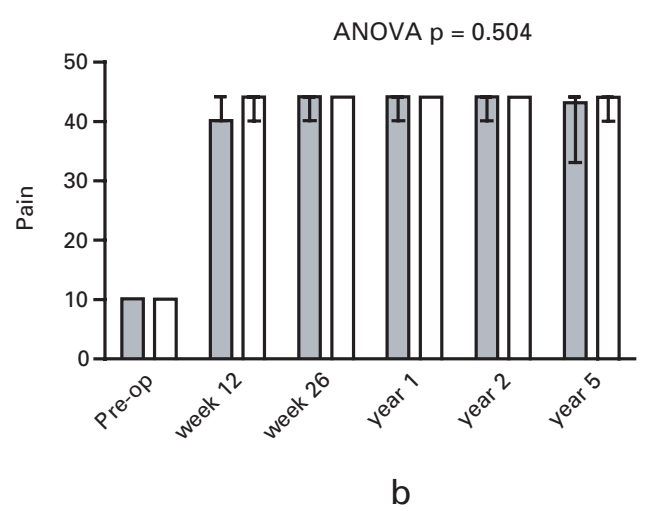

ANOVA $p=0.093$

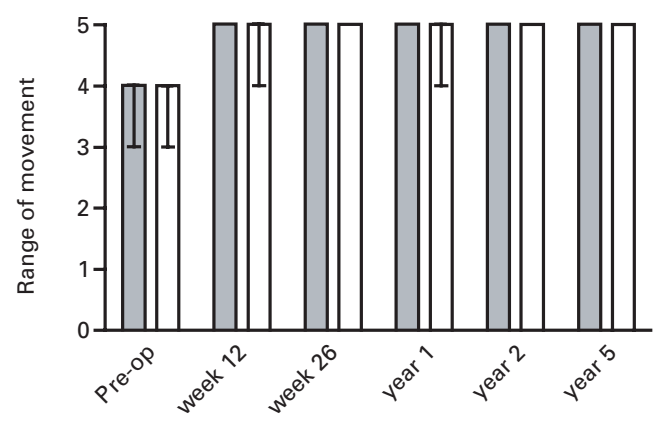

d

Fig. 1

Harris hip scores of the patients over five years showing a) the overall score; b) the pain component; c) the functional (including deformity) component and d) the range of movement. The error bars give the median \pm the interquartile range.

study (Fig. 1a). The baseline scores were similar in both groups, and most improvement in scores occurred during the first 12 weeks. At five years there was a trend toward a poorer Harris hip score in the pamidronate group without reaching statistical significance. Examination of the three principal domains of the score (pain, function including deformity and range of movement) showed that this trend lay in the functional component of the summary score, but was also not significant (Figs $1 \mathrm{~b}$ to $1 \mathrm{~d}$ ). The data from the principal domains also showed that the scores for pain and range of movement underwent the most rapid improvement, with most occurring during the first 12 weeks whereas functional improvement occurred more slowly but continued for up to one year after surgery.

Isolated expansile osteolytic lesions were identified on anteroposterior radiographs of the hip at five years in four patients (two in each group; chi-squared test $\mathrm{p}=0.954$ ), but none had evidence of loosening on plain radiographs. In three patients (two placebo, one pamidronate) cavitary osteolytic lesions (Fig. 2) were seen in the region of the

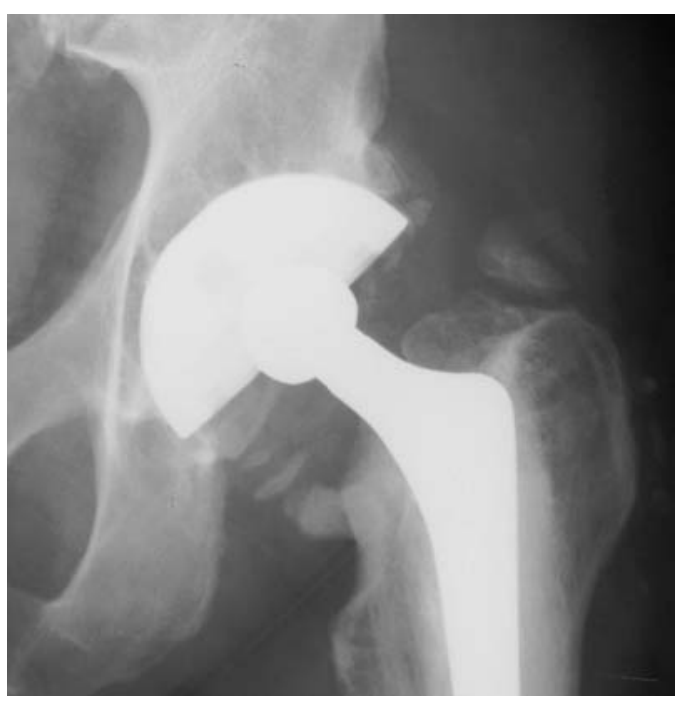

Fig. 2

Radiograph of the pelvis showing a small osteolytic lesion in the acetabular dome. 


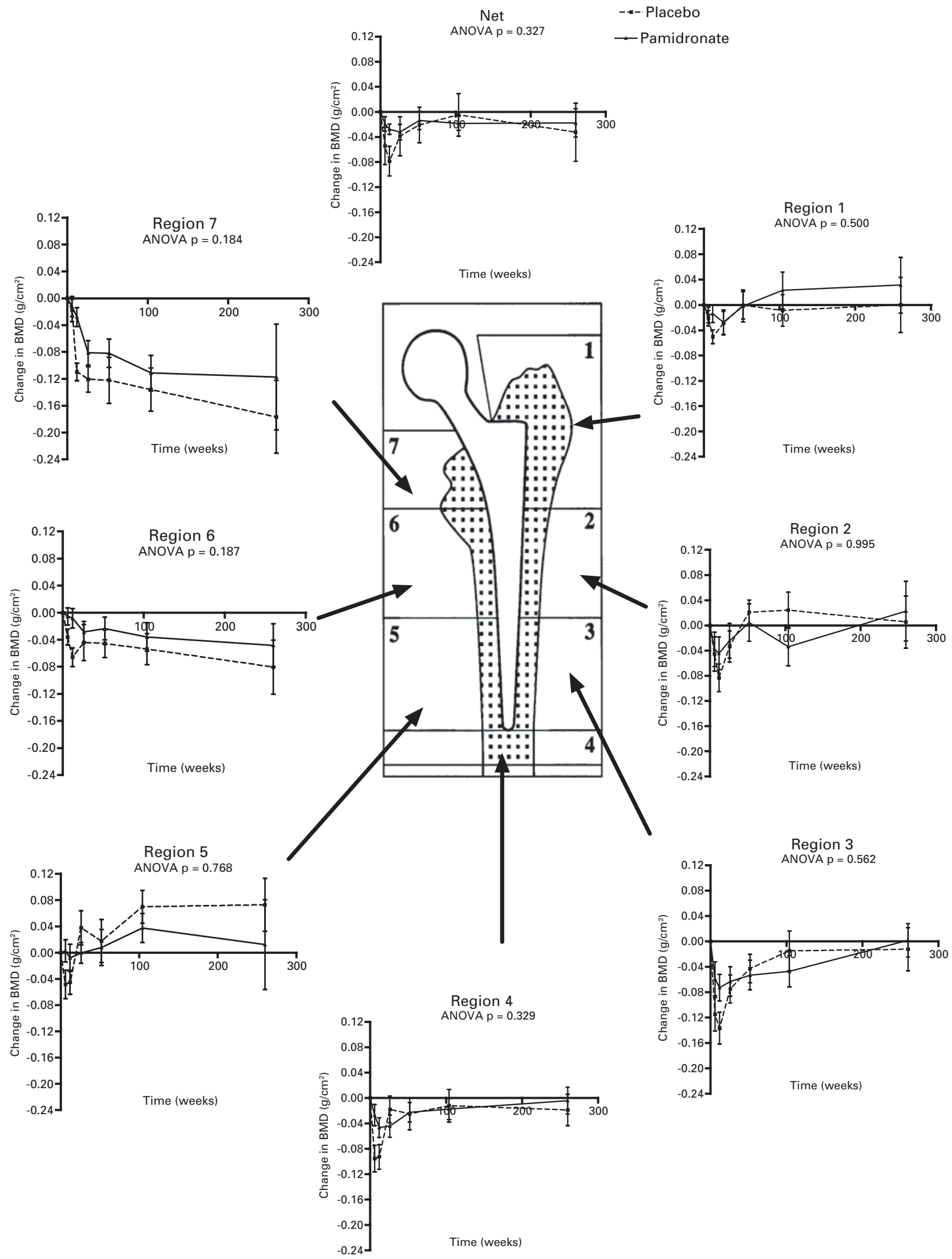

Fig. 3

The mean ( \pm SEM) change in regional femoral bone mineral density $(B M D)\left(\mathrm{g} / \mathrm{cm}^{2}\right)$ over five years in both groups. 


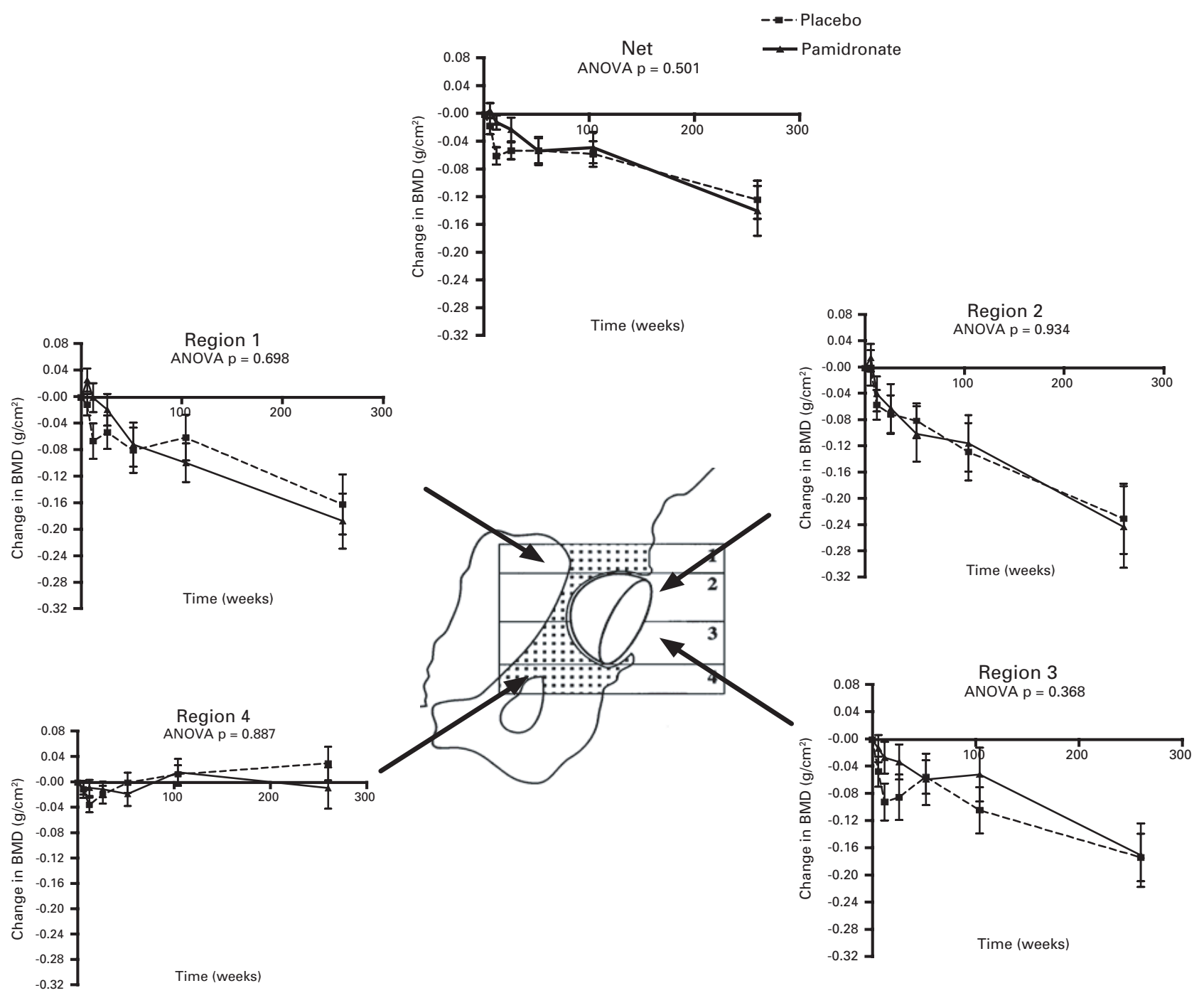

Fig. 4

The mean $\left( \pm\right.$ SEM) change in the regional pelvic bone mineral density $(B M D)\left(g / \mathrm{cm}^{2}\right)$ over five years in both groups.

acetabular dome, the largest measuring $18 \mathrm{~mm} \times 9 \mathrm{~mm}$. In one patient an osteolytic lesion measuring $4.5 \mathrm{~mm} \mathrm{x}$ $8.1 \mathrm{~mm}$ was noted in the region of the femoral calcar. Three of the patients with osteolysis were asymptomatic and one reported pain. No linear osteolytic lesions were seen in either group.

Bone densitometry. The pre-operative femoral BMD was similar in both groups (Table I). In the placebo group it declined rapidly in the first 12 weeks after surgery in all regions (Fig. 3), followed by a recovery phase in all zones except regions 6 and 7, which showed further decline. Treatment with pamidronate resulted in a consistent trend towards less bone loss in regions 6 and 7 in all the postoperative stages, although this did not reach statistical significance (Fig. 3; region 6, ANOVA, p $=0.187$; region 7, ANOVA, $p=0.184)$. No differences between the groups were found for the other regions of interest in the femur over the five-year period.

The pre-operative BMD for the acetabulum was similar in both groups (Table I). In the placebo group the pelvic BMD declined rapidly over the first 12 weeks after surgery in all regions (Fig. 4). Continued bone loss was seen throughout the five years in all regions, except in region 4 in which there was subsequent recovery in the BMD. Bone loss was most severe in the region of the acetabular dome, in regions 2 and 3. Treatment with pamidronate did not influence the loss of BMD over the five-year period (ANOVA, $\mathrm{p}>0.05$ all regional comparisons).

Adverse events. The adverse events in the initial two years after surgery have been described in our previous studies. ${ }^{12,13}$ Over the subsequent three years, five of 19 patients $(26 \%)$ in the placebo group and seven of $18(39 \%)$ in the 
pamidronate group experienced such problems (chisquared test, $\mathrm{p}>0.05)$. In the placebo group two developed hypertension, one had a chest infection, one underwent lobectomy for bronchiectasis and one had a fracture of the ankle and also underwent prostatectomy. In the pamidronate group, diabetes with peripheral neuritis was detected in one patient, one had a peptic ulcer, one had angina which required insertion of coronary stents, one underwent repair of an inguinal hernia, one developed an ear infection, one had a fracture of the neck of the femur on the contralateral side which required screw fixation and one suffered a dislocation of the hip which was treated by closed reduction.

\section{Discussion}

Previous studies examining the role of bisphosphonates after THR have had a short follow-up and have focused mainly on peri-prosthetic changes in the BMD. ${ }^{12,14-16}$ Our study evaluated the effect of pamidronate on the clinical and radiological outcome over a period of five years. We found that a single post-operative dose of pamidronate did not affect the clinical outcome after THR, nor did it prevent the development of osteolytic lesions. The incidence of osteolytic lesions in our study population was high $(9.5 \%)$. Possible reasons for this include the relatively young mean age of the patients (58 years; 28 to 73 ) and a high mean linear wear of the acetabular polyethylene at five years of $0.90 \mathrm{~mm}$ and $0.60 \mathrm{~mm}$ in the pamidronate and placebo groups, respectively (Table I).

We have previously described the significant effect of a single dose of pamidronate in preserving acetabular and femoral bone mass at six months after the operation, ${ }^{12}$ and that subsequently its efficacy was lost on the acetabular site. ${ }^{13}$ Our data at five years suggest that the effect of this therapy on the femoral side after a single dose was also lost in the long term. However, this loss of significance may have been a result of reduced statistical power at the fiveyear stage because of the withdrawal of patients, since the trend towards preservation of the bone mass remained (Fig. 3 ). Using the alternative approach of 'per-hip' analysis (42 hips), rather than 'per-patient' (37), the trend towards preservation of the bone mass for regions 6 and 7 remained significant over the five-year period (region 6, ANOVA, $\mathrm{p}=$ 0.038; region 7 ANOVA, $\mathrm{p}=0.048$ ). Wang et $\mathrm{al}^{17}$ have recently noted a similar loss in efficacy in preservation of the distal femoral BMD at three years after the cessation of treatment with alendronate in total knee replacement. Their data also showed a trend towards preservation of the bone mass in the bisphosphonate group compared with a control group (BMD change $-3.9 \%$ vs $-12.2 \%$, respectively, $\mathrm{p}=0.08)$. Taken together, these studies suggest that maintenance doses would be required to have a clear effect on the preservation of the peri-prosthetic bone mass in the long term after total joint replacement. However, the impact of preservation of the bone mass in relation to the risk of aseptic loosening remains unknown, ${ }^{25}$ and such therapy outside the setting of clinical trials cannot be justified based on current evidence.

The observed lack of an effect in inhibiting osteolysis may be due to a primary inability of pamidronate to influence peri-prosthetic osteolysis, or it may be a function of an insufficient dose. Previous studies in small and large animal models have suggested a potential role for other bisphosphonates in inhibiting osteolysis. Von Knoch et $\mathrm{al}^{26}$ reported a favourable effect of a single dose of zolendronic acid on particle-induced osteolysis in mice. Studies in a rat model by Millett, Alen and Bostrom, ${ }^{27}$ and in a canine model by Shanbhag, Hasselman and Rubash, ${ }^{28}$ have also shown that alendronate can inhibit particle-induced osteolysis. However, a clinical study has not shown a similar effect in man. ${ }^{9}$ Rubash et $\mathrm{al}^{9}$ found that daily oral administration of $10 \mathrm{mg}$ or $35 \mathrm{mg}$ of alendronate did not have any effect on decreasing the progression of established femoral osteolytic lesions in 123 patients studied over 18 months. The results of these studies suggest that the timing of the administration of bisphosphonate in relation to the development of osteolysis and the type of bisphosphonate used may be important. ${ }^{9,27,28}$ The successful animal studies differ from those in clinical practice in that the bisphosphonate was given at a similar time to the osteolytic stimulus (particles), and that bisphosphonate was started before osteolytic lesions were established. ${ }^{27,28}$ The nearest clinical situation to that of the animal models may be in the commencement of prophylactic administration in patients with established high wear rates of the implant, given before the development of osteolytic lesions.

The regional pattern of the longitudinal peri-prosthetic change in the BMD around a cemented, polished, collarless, double-tapered femoral implant over the period studied has not been described previously. The data from our control and treatment groups suggested that the overall magnitude of bone loss associated with use of this design of implant was small. This may be a reflection of the force-closed design principle, ${ }^{29}$ allowing more proximal load transfer to host bone than shape-closed implant designs. By contrast, acetabular bone loss was greater than that around the femoral component and was progressive over the five-year period, occurring predominantly at the acetabular dome suggesting a rim-loading pattern of load transfer, as previously proposed for uncemented metal-backed acetabular components. $^{30}$

Our study has a number of limitations. We recruited 50 patients at the start, but only 37 could be included in the analysis at five years. Also, the study was powered to examine changes in the BMD and not osteolysis. We used plain radiography to assess the osteolytic lesions, and it is possible that the number of lesions detected may be higher with the use of advanced imaging techniques such as CT or MRI. $^{31}$

In summary, although single-dose post-operative pamidronate therapy is effective at reducing bone loss at two years, this effect is not sustained over five years. 
We wish to thank the staff of the Metabolic Bone Centre, Northern General Hospital, Sheffield for their help with the study. We would also like to thank the British Orthopaedic Association (Wishbone Trust), Arthritis Research Campaign John Charnley Trust, and the Cavendish Trust for providing grant support for this study, and Novartis Inc for providing pamidronate for the purposes of this study.

No benefits in any form have been received or will be be received from a commercial party related directly or indirectly to the subject of this article.

\section{References}

1. Archibek MJ, Jacobs JJ, Black J. Alternative bearing surfaces in total joint arthroplasty: biologic considerations. Clin Orthop 2000;379:12-21.

2. Digas G, Karrholm J, Thanner J, Malchau H, Herberts P. Highly cross-linked polyethylene in cemented THA: randomized study of 61 hips. Clin Orthop 2003;417: 126-38.

3. Tanzer M, Kantor S, Rosenthall L, Bobyn JD. Femoral remodeling after porouscoated total hip arthroplasty with and without hydroxyapatite-tricalcium phosphate coating: a prospective randomized trial. J Arthroplasty 2001;16:552-8.

4. Bhandari M, Bajammal S, Guyatt $\mathbf{G H}$, et al. Effect of bisphosphonates on periprosthetic bone mineral density after total joint arthroplasty: a meta-analysis. J Bone Joint Surg [Am] 2005;87-A:293-301.

5. Schwarz EM, Campbell D, Totterman S, et al. Use of volumetric computerized tomography as a primary outcome measure to evaluate drug efficacy in the prevention of peri-prosthetic osteolysis: a 1-year clinical pilot of etanercept vs. placebo. J Orthop Res 2003;21:1049-55.

6. Pollice PF, Rosier RN, Looney RJ, et al. Oral pentoxifylline inhibits release of tumour necrosis factor-alpha from human peripheral blood monocytes: a potentia treatment for aseptic loosening of total joint components. J Bone Joint Surg [Am] 2001:83-A:1057-61.

7. Carmody EE, Schwarz EM, Puzas JE, Rosier RN, O'Keefe RJ. Viral interleukin10 gene inhibition of inflammation, osteoclastogenesis, and bone resorption in response to titanium particles. Arthritis Rheum 2002;46:1298-308.

8. Ulrich-Vinther M, Carmody EE, Goater JJ, et al. Recombinant adeno-associated virus-mediated osteoprotegerin gene therapy inhibits wear debris-induced osteolysis. J Bone Joint Surg [Am] 2002;84-A:1405-12.

9. Rubash HE, Dorr LD, Jacobs J, et al. Does alendronate inhibit the progression of periprosthetic osteolysis? Trans ORS 2004;29:1492.

10. Pandey R, Quinn JM, Sabokbar A, Athanasou NA. Bisphosphonate inhibition of bone resorption induced by particulate biomaterial-associated macrophages. Acta Orthop Scand 1996:67:221-8.

11. Russell RG, Rogers MJ. Bisphosphonates: from the laboratory to the clinic and back again. Bone 1999;25:97-106.

12. Wilkinson JM, Stockley I, Peel NF, et al. Effect of pamidronate in preventing local bone loss after total hip arthroplasty: a randomised, double-blind, controlled trial. J Bone Miner Res 2001;16:556-64.

13. Wilkinson JM, Eagleton AC, Stockley I, et al. Effect of pamidronate on bone turnover and implant migration after total hip arthroplasty: a randomized trial. J Orthop Res 2005:23:1-8.
14. Soininvaara TA, Jurvelin JS, Miettinen HJ, et al. Effect of alendronate on periprosthetic bone loss after total knee arthroplasty: one-year, randomized, controlled trial of 19 patients. Calcif Tissue Int 2002;71:472-7.

15. Venesmaa PK, Kroger HP, Miettinen HJ, et al. Alendronate reduces periprosthetic bone loss after uncemented primary total hip arthroplasty: a prospective randomized study. J Bone Miner Res 2001;16:2126-31.

16. Wang CJ, Wang W, Weng LH, et al. The effect of alendronate on bone mineral density in the distal part of the femur and proximal part of the tibia after total knee arthroplasty. J Bone Joint Surg [Am]2003;85-A:2121-6.

17. Wang CJ, Wang JW, Ko JY, Weng LH, Huang CC. Three-year changes in bone mineral density around the knee after a six-month course of oral alendronate following total knee arthroplasty: a prospective, randomized study. J Bone Joint Surg [Am] 2006;88-A:267-72.

18. Harris WH. Traumatic arthritis of the hip after dislocation and acetabular fractures: treatment by mold arthroplasty. An end-result study using a new method of result evaluation. J Bone Joint Surg [Am] 1969;51-A:737-55.

19. DeLee JG, Charnley J. Radiological demarcation of cemented sockets in total hip replacement. Clin Orthop 1976;121:20-32

20. Gruen TA, McNiece GM, Amstutz HC. "Modes of failure" of cemented stem-type femoral components: a radiographic analysis of loosening. Clin Orthop 1979;141:17-27.

21. Wilkinson JM, Hamer AJ, Elson RA, Stockley I, Eastell R. Precision of EBRA Digital software for monitoring implant migration after total hip arthroplasty. $J$ Arthroplasty 2002;17:910-16.

22. Wilkinson JM, Peel NF, Elson RA, Stockley I, Eastell R. Measuring bone minera density of the pelvis and proximal femur after total hip arthroplasty. J Bone Joint Surg [Br] 2001;83-B:283-8.

23. Larsen MB, Nielsen PT, Soballe K. DXA scanning of acetabulum in patients with cementless total hip arthroplasty. J Clin Densitom 2005;8:476-83.

24. Shetty NR, Hamer AJ, Stcokley I, Eastell R, Wilkinson JM. Precision of periprosthetic bone mineral density measurements using Hologic Windows versus DOS based analysis software. J Clin Densitom 2006;9:363-6.

25. Karachalios T, Tsatsaronis C, Efraimis G, et al. The long-term clinical relevance of calcar atrophy caused by stress shielding in total hip arthroplasty: a 10-year, prospective, randomized study. J Arthroplasty 2004;19:469-75.

26. von Knoch M, Wedemeyer C, Pingsmann A, et al. The decrease of particle-induced osteolysis after a single dose of bisphosphonate. Biomaterials 2005;26:1803-8.

27. Millett PJ, Alen MJ, Bostrom MP. Effects of alendronate on particle-induced osteolysis in a rat model. J Bone Joint Surg [Am] 2002;84-A:236-49.

28. Shanbhag AS, Hasselman CT, Rubash HE. The John Charnley Award: inhibition of wear debris mediated osteolysis in a canine total hip arthroplasty model. Clin Orthop 1997;344:33-43

29. Huiskes R, Verdonschot N, Nivbrant B. Migration, stem shape, and surface finish in cemented total hip arthroplasty. Clin Orthop 1998;355:103-12

30. Levenston ME, Beaupre GS, Schurman DJ, Carter DR. Computer simulations of stress-related bone remodeling around noncemented acetabular components. J Arthroplasty 1993:8:595-605.

31. Walde TA, Weiland DE, Leung SB, et al. Comparison of CT, MRI, and radiographs in assessing pelvic osteolysis: a cadaveric study. Clin Orthop 2005:437:138-44. 